\title{
AVALIAÇÃO FISIOTERAPÊUTICA EM CRIANÇA COM MALFORMAÇÃO CONGÊNITA DE MEMBRO INFERIOR: UM RELATO DE CASO
}

\section{Renan Nunes Aguiar}

Discente dos cursos de Fisioterapia e Pedagogia da Universidade de Franca, Brasil.

\section{Alana Borges da Silva Santos}

Discente do curso de Fisioterapia da Universidade de Franca. Brasil.

\section{Raquel Amanda da Silva Gontijo}

Discente do curso de Fisioterapia da Universidade de Franca., Brasil.

\section{Giovanna Oliveira Beraldo}

Discente do curso de Fisioterapia da Universidade de Franca., Brasil.

\section{Sabrina Garcia Martins}

Discente do curso de Fisioterapia da Universidade de Franca., Brasil.

\section{Ana Paula Oliveira Borges}

Doutora em Ciências Médicas pela Universidade de São Paulo (USP). Docente do curso de Fisioterapia da Universidade de Franca, Brasil.
RESUMO: Este trabalho teve como objetivo realizar uma avaliação fisioterapêutica em um voluntário com malformação congênita do membro inferior direito, a fim de conhecer seus aspectos motores e funcionais, devido ao fato de ser um caso peculiar com incidência de 1 a cada 100.000 nascidos vivos. Tratou-se de um relato de caso, realizado na clínica escola de fisioterapia de uma universidade do interior do Estado de São Paulo. Os procedimentos consistiram em: anamnese, exame físico, escalas e instrumentos de avaliação do controle, índice de Barthel modificado, plataforma de força e avaliação postural. Pode-se observar através da avaliação fisioterapêutica alterações posturais relevantes com assimetrias entre os hemicorpos, déficit de equilíbrio e diminuição de força muscular no membro inferior direito, o que acarreta uma alteração biomecânica importante no participante avaliado. Essas informações coletadas durante as avaliações são essenciais para conhecer as alterações físicas decorrentes da malformação congênita para promover um melhor direcionamento em seu tratamento.

PALAVRAS-CHAVE: Crianças; Desenvolvimento Ósseo; Fisioterapia; Membros Artificiais.

\section{PHYSIOTHERAPY EVALUATION IN CHILDREN WITH CONGENITAL MALFORMATION OF LOWER MEMBERS: A CASE STUDY}

\begin{abstract}
A physiotherapy evaluation has been undertaken with a voluntary subject with congenital malformation of the right lower limber to understand motor and functional aspects of the issue. The fact has an occurrence of 1/100000 live births. The case study has been undertaken in a physiotherapy school at a university clinical in the interior of the state of São Paulo, Brazil. Procedures included anamnesis, physical examination, scales and instruments for control assessment, modified Barthel Index, force platform and posture evaluation. Physiotherapeutic evaluation revealed significant posture changes with asymmetry between the hemibodies, deficit in equilibrium and lessening of muscular force in the right lower member, with subsequent important biomechanical changes in the patient. Information collected during evaluations is essential to understand the physical alternations due to congenital malformation for better results through treatment.
\end{abstract}

KEY WORDS: Children; Bone development; Physiotherapy; Artificial limbs. 


\section{INTRODUÇÃO}

As malformações congênitas definem-se como alterações estruturais, funcionais ou metabólicas e estão presentes desde o desenvolvimento embrionário até o nascimento, ocorrem anomalias físicas e/ou mentais que são de diferentes complexidades clínicas ${ }^{1}$. Geralmente as deficiências ocorrem por uso de medicamentos e outras drogas consumidas pela mãe, entre a quarta e a oitava semana de vida intrauterina, mas também podem desencadear-se por fatores como: prematuridade, desnutrição materna, exposição à radiação, causas metabólicas e fatores genéticos ${ }^{2}$.

As crianças afetadas podem apresentar agnesia completa ou parcial do segmento do membro e malformação de órgãos internos ${ }^{2}$. As anomalias mais frequentes acometem o sistema nervoso central, causando anencefalia, lábio leporino e mielomeningocele, no sistema cardiovascular ocorrem as cardiopatias congênitas, no sistema visual deficiências como a cegueira e no sistema musculoesquelético são prevalentes as deficiências nos membros, como as malformações dos dedos, pé torto congênito e luxação congênita de quadril ${ }^{3}$.

Os membros inferiores são compostos por segmentos como: quadril, coxas, joelhos, pernas e pés. Quando ocorre a não formação ou malformação desses membros podem estar ausentes estruturas ósseas como a tíbia, por exemplo, e conter outras estruturas ósseas no local como tarso e metatarsos, formando o pé ${ }^{4}$. Geralmente, quando há esse tipo de anomalia gera dificuldades no equilíbrio e o uso de prótese pode ser necessário².

A deficiência congênita do fêmur (DCF) desencadeia comprometimentos como restrição nos movimentos do quadril, limitação articular e contraturas nos tendões e músculos. A criança encontra-se com um quadril em abdução, flexão e rotação externa e a discrepância entre os membros causa grande alteração na deambulação. A Hemimelia Fibular e Tibial são malformações congênitas raras onde ocorre ausência parcial ou total do segmento, o membro é encurtado, há alterações na articulação do joelho, deformidades do tornozelo e malformações variadas no pés.

As crianças e os lactentes que nascem com comprometimento biomecânico, principalmente lesões nos membros inferiores, possuem algumas limitações ou atrasos para o desenvolvimento motor como: rolar, sentar, engatinhar, levantar, andar, estender as mãos para pegar objetos. Durante a marcha geralmente elas necessitam de ajuda para ficar em pé, seu gasto energético é maior na fase de propulsão do que a marcha de uma criança sem limitações, e seu centro de gravidade geralmente é deslocado e as crianças que fazem uso de aparelhos mecânicos, como andador, cadeira de rodas, muletas são mais propensos a desenvolver problemas posturais ${ }^{2}$.

O fisioterapeuta tem como objetivo, desde o nascimento da criança aos 12 a 18 meses de idade, avaliar e auxiliar na evolução do seu desenvolvimento motor, ganhar força muscular, amplitude de movimento e proporcionar exercícios de alongamento evitando as possíveis contraturas e manter a funcionalidade do membro acometido. Dos 12-18 meses aos 24 meses será escolhida a prótese mais indicada para a criança e a fisioterapia estimulará a posição ortostática, transferência de peso para o membro com a prótese e a aquisição da marcha. Após os 24 meses a marcha é adquirida em planos totalmente diferentes. Assim, cabe ao fisioterapeuta proporcionar atividades que facilitem o cotidiano da criança promovendo maior independência, e avaliar as condições do membro acometido e da prótese ${ }^{5}$. Sendo assim, a fisioterapia é primordial e imprescindível para a reabilitação destes pacientes e deve abranger desde o desenvolvimento neuropsicomotor, postura, equilíbrio, atividades de vida diária, protetização e marcha até as orientações para a família e a melhora da qualidade de vida ${ }^{6}$.

Dessa maneira, por ser um caso peculiar com incidência de 1 a cada 100.000 nascidos vivos, o objetivo deste estudo foi realizar uma avaliação fisioterapêutica em um voluntário com malformação congênita do membro inferior direito (MID), que se encontra com uso de prótese, a fim de conhecer seus aspectos motores e funcionais e poder monitorar a doença e guiar as e intervenções necessárias.

\section{METODOLOGIA}

Trata-se de um estudo observacional, de corte transversal e descritivo do tipo relato de caso que foi rea- 
lizado em uma clínica escola de fisioterapia de uma universidade do interior do Estado de São Paulo. O estudo obedeceu aos princípios éticos e legais, sendo iniciada a pesquisa após aprovação do Comitê de Ética em Pesquisa da mesma instituição, com esclarecimento sobre os procedimentos avaliativos e assinatura do Termo de Consentimento Livre e Esclarecido (TCLE) pelo responsável do participante (protocolo CAAE 44637515.0.0000.5495). Fez parte do estudo um participante com diagnóstico clínico de má formação congênita de fêmur, do sexo masculino, com 8 anos de idade, atendido na clínica de fisioterapia.

Inicialmente o participante apresentou uma radiografia convencional atual de membros inferiores para análise óssea visual. Foi realizada a avaliação padronizada utilizada no setor de Fisioterapia Neurológica da clínica de Fisioterapia, sendo observados os seguintes tópicos: sensibilidade superficial e profunda, propriedades biomecânicas, grau da amplitude de movimento (ADM), força muscular, avaliação do movimento funcional, tônus muscular, reflexos, coordenação motora, avaliação da funcionalidade de atividades estáticas e dinâmicas, habilidade motora fina e função nas atividades de vida diária.

Posteriormente, foram realizadas as mensurações reais e aparentes da discrepância dos membros inferiores e mensuração da obliquidade pélvica ${ }^{7}$. Para mensuração aparente foi verificada a distância da cicatriz umbilical ao maléolo medial e para medida real foi verificada a distância entre as espinhas ilíacas ântero-superiores (EIAS) até o maléolo medial e para medida da obliquidade pélvica foi feita a mensuração da cicatriz umbilical a EIAS bilateralmente. Foi considerada discrepância entre os membros uma diferença acima de $1 \mathrm{~cm}$, entre um membro e o outro ${ }^{8}$.

Foram aplicados escalas e instrumentos de avaliação do controle postural que verificou os aspectos motores e funcionais do participante.

Foi utilizado o índice de Barthel modificado, traduzido, adaptado e validado no Brasil para a avaliação da funcionalidade. O índice de Barthel é um método quantitativo para avaliação do grau de independência na realização de atividades de vida diária (AVD ’s), que permite uma graduação entre máxima dependência ( 0 pontos) e máxima independência (100 pontos) $)^{9}$. O escore encon- trado na escala aplicada foi descrito em forma de pontuação, com valor absoluto.

Na avaliação do controle postural, o participante estava vestido com short de banho e descalço. O controle postural Fo inicialmente examinado utilizando uma plataforma de força BIOMEC 400 v1.1 (EMG System do Brasil $\left.{ }^{\circledR}\right)$. O participante foi instruído a realizar a tarefa de apoio bipodal, permanecendo o mais estático possível, sobre o centro da plataforma de força, em posição ortostática, ou seja, com os braços ao longo do corpo e olhar para um ponto fixo na parede, em que já estava marcado $^{10}$.

A plataforma de força fornece informações do componente vertical da força de reação do solo, a partir das quais é estimado o centro de pressão (COP). Os sinais da plataforma de força foram adquiridos em uma frequência de $100 \mathrm{~Hz}$. Foi realizado um registro com duração de 60 segundos.

Os dados provenientes da plataforma de força foram analisados por meio de software específico da EMG System do Brasil@, o qual processa os dados referentes às forças exercidas sobre a plataforma na direção vertical e, a partir destes dados, são calculadas as seguintes variáveis: amplitude média de oscilação e velocidade média do deslocamento do Centro de Pressão (COP), para as direções anteroposterior (AP) e médio-lateral (ML).

Posteriormente à avaliação com a plataforma de força foi realizada a avaliação postural utilizando a avaliação padronizada e os mesmos pontos de referência utilizados na biofotogrametria computadorizada, através do software para avaliação postural (SAPO) investigadas através de fotointerpretação ${ }^{11}$. Para a avaliação postural, o participante se submeteu previamente a demarcações nos pontos anatômicos referenciais, e as imagens captadas deveriam ser de boa qualidade para uma adequada interpretação.

O participante foi fotografado na posição de avaliação postural nas vistas anterior, posterior e laterais direita e esquerda, com e sem o uso de prótese.

Os pontos anatômicos referenciais para a recolha das imagens foram demarcados correspondendo aos ângulos: plano ântero-posterior: lóbulo das orelhas, extremidade acromial e esternal das clavículas, ângulo superior e inferior das escápulas, cristas ilíacas ântero- 
superior e póstero superior, joelhos, coluna cervical, torácica e lombar e plano perfil: epicôndilos laterais, maléolos fibulares e tibiais ${ }^{12}$.

Os achados clínicos e escores encontrados nos instrumentos utilizados foram descritos em forma de pontuações, com valores absolutos e foram discutidos e comparados com a literatura.

\section{RESULTADOS}

Paciente, oito anos, com diagnóstico clínico de malformação congênita em MID, tendo como maior queixa principal dor nos membros inferiores (MMII), realiza fisioterapia e uso de prótese há 6 anos. Os resultados das avaliações podem ser vistos a seguir:

\section{EXAME DE IMAGEM}

O exame de radiografia evidenciou a malformação no fêmur direito, apresentando arqueado com uma convexidade lateralmente e menor comprimento em relação ao fêmur esquerdo. Foi observada anomalia na formação e localização dos ossos tíbia e fíbula direitos. Há uma luxação da tíbia, cujo seu $1 / 3$ superior é deformado e a epífise articulando medialmente com o $1 / 3$ inferior do fêmur. A fíbula é hipoplásica e articula-se com a epífise do fêmur. Esses ossos se encontram localizados paralelos ao fêmur direito com possibilidade de impactação óssea. Não há evidências radiológicas de formação correta do tornozelo. Não há alterações ósseas na formação da articulação coxofemural, mas é evidente a discrepância na altura comparativa entre os ossos da pelve, com o lado direito da pelve se mostrando mais baixo que o esquerdo. O fêmur, tíbia e fíbula esquerdos não apresentam alterações. As imagens podem ser visualizadas na Figura 1.

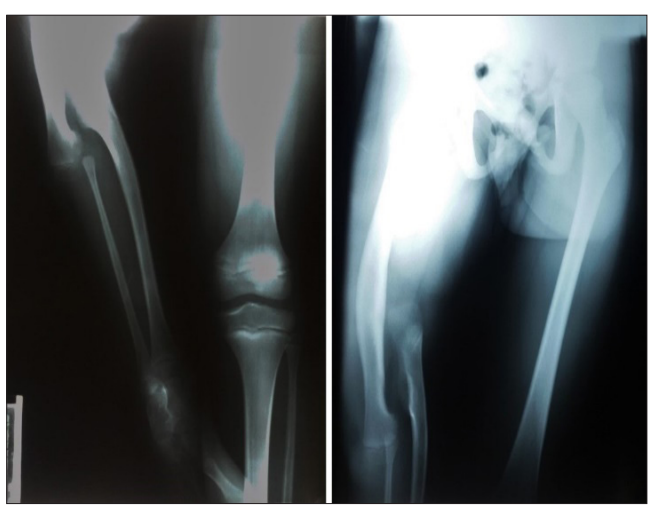

Figura 1. Evidências PA da radiografia.

\section{AVALIAÇÃO NEUROLÓGICA}

Foram observadas alterações nas propriedades biomecânicas dos músculos como ausência de ADM em flexão e extensão do joelho direito, ausência de força muscular (grau 0) em flexores e extensores do joelho direito e diminuição de força muscular em flexores e extensores do quadril (grau 3) e abdutores de quadril (grau 2). A avaliação dos reflexos profundos evidenciou arreflexia patelar do lado direito. A coordenação motora apresentou comprometimento mínimo em realizar atividades como: desenhar um círculo com o pé. Já nas atividades que exigem equilíbrio (realizada com a prótese) ficar em apoio unipodal foi considerada atividade impossível. As habilidades funcionais estáticas foram alteradas nas posturas ajoelhado, semi-ajoelhado e em pé. O participante transfere-se para posição ajoelhada com auxílio, mantém sem apoio e sem alinhamento, da posição semi-ajoelhada para transferência em pé, o paciente realiza sem auxílio, mantém sem apoio e sem alinhamento, na avaliação das habilidades funcionais dinâmicas as atividades foram realizadas em padrão normal e coordenadas, porém com alterações qualitativas, fazendo uso da prótese para locomoção.

\section{ÍNDICE DE BARTHEL}

A escala de Barthel evidenciou que o participante consegue realizar as atividades de vida diária de maneira independente. Essa avaliação mostrou que ele consegue se adaptar principalmente nas atividades que requerem uso dos MMII com auxílio da prótese. Esses resultados podem ser melhor observados na Tabela 1 . 
Tabela 1. Valores das Atividades de Vida Diária

\begin{tabular}{|l|c|}
\hline FUNÇÃo & PONTUAÇÃo \\
\hline Alimentação & 1 \\
\hline Banho & 1 \\
\hline Higiene Pessoal & 1 \\
\hline Vestimenta & 1 \\
\hline Transferência no banheiro & 1 \\
\hline Transferências/Cadeira e cama & 1 \\
\hline Deambulação & 1 (com órtese) \\
\hline Subir escadas & 1 \\
\hline
\end{tabular}

0: incapaz de realizar; 1 : independente; 2 necessita de ajuda.

\section{ESTABILOMETRIA}

As variáveis avaliadas a partir dos sinais da plataforma de força para quantificar a estabilidade postural foram o deslocamento do centro de pressão (COP) em $\mathrm{cm}^{2}$, a velocidade média da oscilação do $\mathrm{COP} \mathrm{em} \mathrm{cm} / \mathrm{s}$, a frequência média da oscilação do COP em $\mathrm{Hz}$, nas direções ântero-posterior (AP) e médio-lateral (ML). Podem-se observar na Tabela 2 os valores encontrados.

Tabela 2. Valores da análise estabilográfica dos parâmetros da plataforma de força do participante avaliado

\begin{tabular}{|l|l|}
\hline \multicolumn{1}{|c|}{ POSICIONAMENTO } & VALORES \\
\hline Posição média AP [cm]: & 19.22 \\
\hline Posição média ML [cm]: & 19.8 \\
\hline Desvio padrão AP [cm]: & 0.13 \\
\hline Desvio padrão ML [cm]: & 0.12 \\
\hline Deslocamento total [cm]: & 27.65 \\
\hline Amplitude AP [cm]: & 0.75 \\
\hline Amplitude ML [cm]: & 0.8 \\
\hline Deslocamento total [cm]: & 27.65 \\
\hline Área [cm2]: & 3.0 \\
\hline Direção de oscilação [o]: & 15.9 \\
\hline Velocidade AP [cm/s]: & 0.31 \\
\hline Velocidade ML [cm/s]: & 0.29 \\
\hline Frequência mediana AP [Hz]: & 0.2 \\
\hline Frequência mediana ML [Hz]: & 0.13 \\
\hline Frequência média AP [Hz]: & 0.35 \\
\hline Frequência média ML [Hz]: & 0.27 \\
\hline AP: anteroposterior; ML: médiolateral; Cm: centímetros;
\end{tabular}

AP: anteroposterior; ML: médio-lateral; Cm: centímetros; Hz: Hertz.

Os dados do COP adquiridos neste estudo foram visualizados por um estabilograma. O estabilograma é a série temporal do COP em cada uma das direções AP e ML.
De acordo com o estabiolograma, pode-se observar um importante deslocamento ML quando comparado ao deslocamento AP, mostrando que há uma tentativa de ganhar maior estabilidade corporal, uma vez que a tendência corporal é manter o maior deslocamento AP.

\section{AVALIAÇÃO POSTURAL}

$\mathrm{Na}$ análise das fotos foi possível observar alterações posturais nas vistas anterior, laterais e posteriores do paciente com e sem a prótese:

\section{Vista anterior}

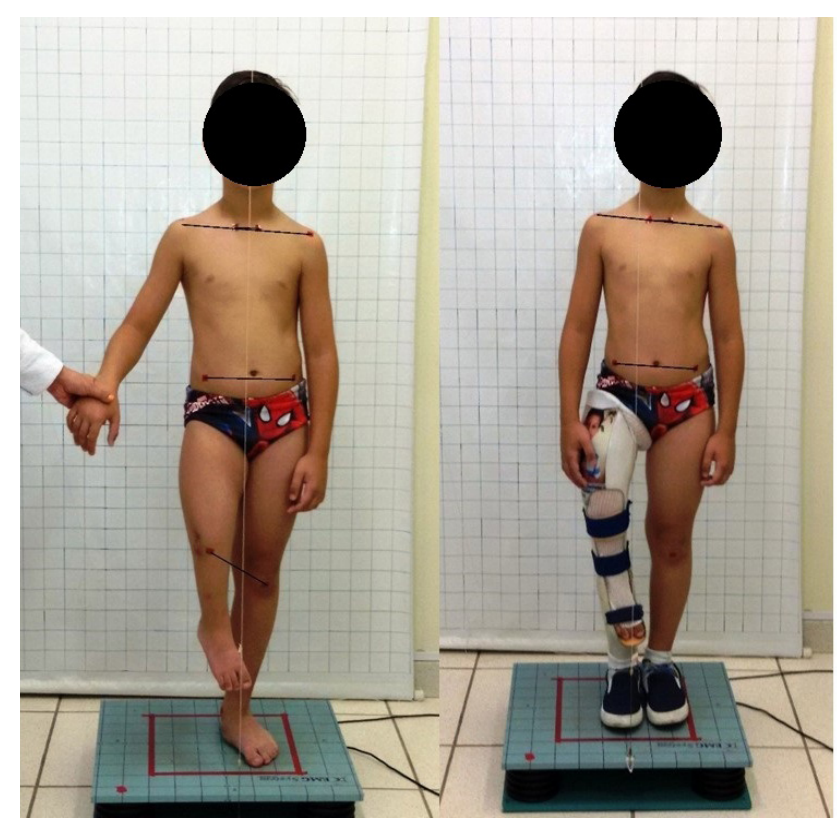

Figura 2. Análise visual sem e com prótese na vista anterior.

Em vista anterior sem prótese (Figura 2), o paciente apresentou inclinação de cabeça à direita, ombro direito elevado, triângulo de Thales assimétrico à direita, tronco em rotação à direita, crista ilíaca ântero-superior esquerda mais elevada que a crista ilíaca ântero-superior direita, quadril com rotação externa à direita, coxa direita em adução, joelhos em genovaro.

Em vista anterior com prótese (Figura 2) foi observada inclinação de cabeça à direita, elevação do ombro direito, assimetria direita em ângulo de Thales, tronco em rotação à direita, assimetria da crista ilíaca direita, quadril com rotação externa e em leve flexão à direita, joelhos em genovaro. 


\section{$>$ Vista lateral}

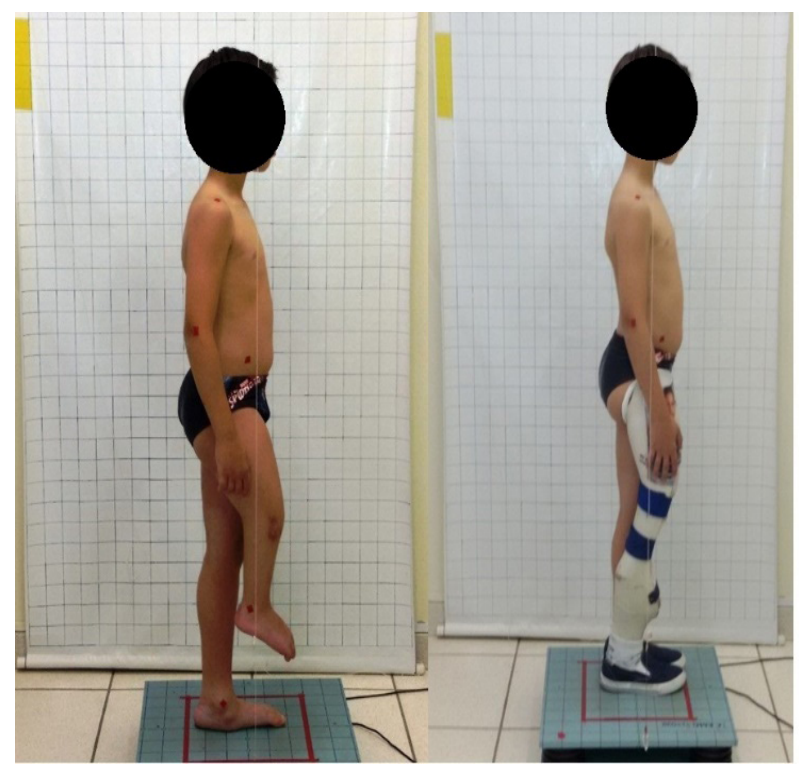

Figura 3. Análise visual sem e com prótese na vista lateral.

Em vistas laterais sem prótese (Figura 3), coluna torácica com hipercifose, coluna lombar com hiperlordose, cintura pélvica em antiversão e flexão do quadril direito.

Foram observadas tais alterações nas Figuras 3 com prótese: ombros protrusos, coluna torácica com hipercifose, coluna lombar com hiperlordose, cintura pélvica em antiversão.

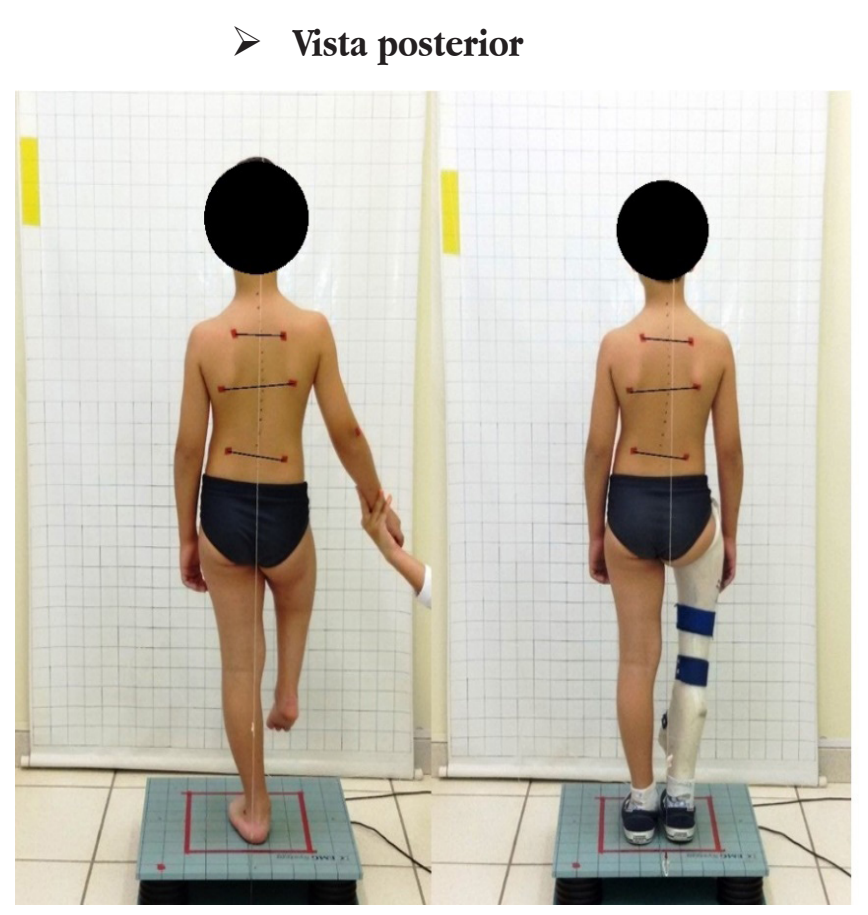

Figura 4. Análise visual sem e com prótese na vista posterior.
O paciente avaliado apresentou tais alterações sem a prótese (Figura 4): escápulas aladas, ângulo inferior da escápula direita mais elevada, coluna toracolombar com escoliose em "C", crista ilíaca póstero-inferior esquerda mais elevada, pregas glúteas assimétricas à direita, pé direito normal e pé esquerdo plano em eversão e com a prótese (Figura 4) apresentou escápulas aladas, ângulo inferior da escápula direita mais elevada, coluna toracolombar com escoliose em "C", assimetria das pregas glúteas, pé direito normal e pé esquerdo plano em eversão.

\section{DISCUSSÃO}

As malformações congênitas são alterações estruturais, funcionais ou metabólicas, podendo gerar alterações físicas e/ou mentais ${ }^{13}$. A criança com comprometimento pode ter agnesia total ou parcial do segmento do membro e apresentar alterações de forma geral na ADM, força muscular, postura corporal, alteração no centro gravitacional e por consequência no equilíbrio estático e dinâmico. Pereira et al. descreveram em seu estudo de corte transversal que cerca de 2,88\% dos recém-nascidos estudados apresentaram algum tipo de anomalia no aparelho locomotor ${ }^{14}$.

$\mathrm{Na}$ literatura, ainda não fica claro o real padrão postural dos pacientes com a malformação congênita em membro inferior, pela falta de estudos de qualidade metodológica e com amostras homogêneas ${ }^{15}$.

De acordo com a avaliação neurológica, foi possível observar uma ausência de força muscular e ADM nos movimentos de flexão e extensão do joelho direito, já para os movimentos de flexão e extensão do ombro, cotovelo, punho e quadril as atividades foram realizadas normalmente, assim como na abdução do ombro, extensão da coluna, flexão do tronco, dorsiflexão e plantiflexão do tornozelo. Nas atividades que exigem equilíbrio, realizadas com a prótese, na posição solicitada para ficar em apoio unipodal no membro inferior direito, foi considerada uma atividade impossível de ser executada, já nas posturas em pé, postura normal e confortável, em pé, olhos fechados e em pé, pés unidos foram atividades possíveis de serem realizadas como também andar ao longo 
de uma linha reta, passar obstáculos e subir escadas ${ }^{16}$.

Nas imperfeições genéticas é provável de se encontrar as deformidades esqueléticas, e vários estudos correlacionam que a imobilidade, alteração no tônus muscular e força podem aumentar os riscos de se obter as deformidades ${ }^{15}$.

Em função disso, através de um estudo transversal e retrospectivo realizado por Novalo et al. ${ }^{17}$, com pacientes de diagnóstico clínico de Osteogênese Imperfeita (OI), e a experiência do Centros de Referência para Tratamento da OI Instituto Fernandes Figueira CROI/IFF, observam grande hipotonia em pacientes, foi intensificada a reabilitação fisioterapêutica, para o aprimoramento do tônus e força muscular em tronco e membros inferiores através de posições do corpo no espaço promovendo maior interação com o sistema vestibular.

A mensuração real e aparente tem como objetivo avaliar as dismetrias dos membros inferiores. A mensuração real em MMII se faz através da medida das espinhas ilíacas ântero superiores (EIAS) até o maléolo medial, e a mensuração aparente é feita da cicatriz umbilical ao maléolo medial. No presente estudo, há uma diferença considerável de $25 \mathrm{~cm}$ de discrepância no membro MID. Em consonância com Junior et al. ${ }^{3}$, um dos fatores que sobrecarregam a coluna e geram prejuízos mecânicos e estéticos, podendo acarretar algumas sequelas, é a desigualdade dos MMII. A mensuração clínica é considerada um método mais exato que tenha, algumas vezes há dificuldades na efetividade devido à falta de precisão na identificação das regiões anatômicas para esta avaliação.

Zamparo et al. ${ }^{4}$ relatam que a locomoção humana ocorre devido às grandezas que atuam sobre o corpo humano torques e forças, possibilitando assim a mudança do corpo no espaço, essas forças podem ser internas e externas, na locomoção humana então acontece um mecanismo chamado pendular, onde há uma minimização do dispêndio energético dos músculos, por meio de uma modificação de energia cinética do centro de massa em potencial gravitacional, onde o inverso também é verdadeiro.

Balardina et al. ${ }^{6}$ dizem que depois das duas guerras mundiais, várias pessoas amputadas precisavam da protetização, sendo assim, a técnica ortopédica progrediu, revelando elementos pré-fabricados e padronizados, para promover durante as sessões de reabilitação uma diminuição do consumo energético. Lawson et al. ${ }^{7}$ argumentam que o gasto energético será maior, com o nível de amputação mais proximal.

Diante Treacy et al. ${ }^{8}$, quando o ser humano deambula apenas um único pé está em contato com o solo, gerando uma maior instabilidade, criando um grande desafio para o sistema de controle do equilíbrio. Youm et al. ${ }^{9}$ dizem que alternar o apoio bipodal para o unipodal é necessário para realização de algumas atividades motoras como: caminhar, girar, subir escadas e se vestir.

Segundo Teixeira et al. ${ }^{10}$ e Silva et al. ${ }^{11}$ a coordenação e o sistema sensório-motor (visual, vestibular e somato-sensorial) estão integrados para a manutenção e correção do sistema muscular no equilíbrio postural. Duncan et al. ${ }^{12}$ relatam que em outras palavras o controle postural acontece pela interação do sistema nervoso central e musculoesquelético que atua através de estratégias preditivas (antecipatórias) e ou/reativas (compensatórias) nas atividades que exijam e equilíbrio e contra o estresse externo que possa prejudicar com que essa atividade aconteça de forma integrada.

As habilidades funcionais estáticas foram alteradas nas posturas ajoelhado, semi-ajoelhado e em pé. $\mathrm{O}$ paciente transfere-se para posição ajoelhada com auxílio, mantém sem apoio e sem alinhamento, da posição semi-ajoelhada para transferência em pé, o paciente realiza sem auxílio, mantém sem apoio e sem alinhamento, na avaliação das habilidades funcionais dinâmicas as atividades são realizadas em padrão normal e coordenadas, porém com alterações qualitativas, fazendo uso da prótese para locomoção.

Krause et al..$^{13}$ expõem que a capacidade de realizar muitas atividades de vida diária de forma independente se torna possível com pré-requisito, uma grande capacidade de controle do equilíbrio.

Foi realizada a avaliação da capacidade funcional por meio do índice de Barthel, o qual mostra o nível de independência funcional nas Atividades de Vida Diárias (AVDs). Os resultados obtidos foram de independência para tais atividades. De acordo com Balardina et al. ${ }^{6}, 40$ pessoas idosas com amputação acima dos maléolos foram entrevistadas e o resultado de sua pesquisa mostrou alto grau de independência para as atividades de vida diária, 
conforme o índice de Barthel. Teve associação significativa somente entre o índice de Barthel e o tipo de amputação, e indicou que são mais independentes os idosos com amputação unilateral do que aqueles com amputação bilateral.

Explanado por Rabello et al..$^{14}$, o corpo humano possui a capacidade de realizar diversas funções complexas e é inevitável a evolução de equipamentos para análise dessas tarefas, a procura por novas ferramentas que sejam capazes de investigar patologias que afetem o equilíbrio, proporcionar através de sistemas maiores mecanismos de avaliação e tratamentos mais efetivos se torna necessário e é possível através da plataforma de força analisar os dados que anteriormente eram somente observados.

Barela e Duarte ${ }^{15}$ descrevem que as plataformas são compostas por duas faces rígidas, uma superior e outra inferior e são unidas por sensores de força sendo típicas três plataformas, uma com um único sensor no centro; plataforma triangular com três sensores nos cantos; e plataforma retangular com sensores nos quatros cantos, sendo o último o mais empregado para avaliação da marcha.

Duarte et al. ${ }^{16}$ determinam plataforma de seis componentes aquelas que através dos sensores medem o torque $\mathrm{Mx}$, My e Mz grandezas que agem acima da plataforma e os três componentes da força, Fx, Fz, Fy (em que $\mathrm{x}, \mathrm{z}$ e y são as direeções ântero-posterior, vertical e médio-lateral, respectivamente).

Novalo et al. ${ }^{17}$ mostram que a plataforma de força pode estar associada a um método de posturografia dinâmica computorizada (PDC) que utiliza um sistema de avaliação computadorizado e quantitativo para o equilíbrio postural e o elemento vestíbulo-espinhal podendo ser executadas em plataformas estáticas (estabilometria ou estatocinesiometria) e dinâmicas (posturografia dinâmica). A estabilometria avalia o equilíbrio na posição ortostática com a monitorização dos deslocamentos do centro de pressão (COP) nas direções lateral (X) e ântero-posterior (Y) da plataforma de força.

Funabashi et al. ${ }^{18}$ narram que frequentemente os testes são executados sobre algumas bases de suporte, tal como pés afastados, juntos e em um só pé. Duarte et al. ${ }^{16}$ descrevem que a plataforma de força é o instrumen- to mais aplicado para a avaliação postural, a medida mais usada é o COP.

Segundo uma pesquisa do tipo estudo de caso experimental, realizada por Carvalho et al. ${ }^{19}$, composta por um paciente com diagnóstico de Malformação de Arnold Chiari tipo I e atendido pelo Serviço de Fisioterapia do Ambulatório de um hospital público, na cidade de Teresina (PI), onde foi submetido à avaliação na estabilometria e baropodometria no começo e no final do tratamento, obteve como resultados na estabilometria após a intervenção fisioterapêutica uma diminuição da amplitude de deslocamento AP (mm), ML(mm) e velocidade média de oscilação $(\mathrm{mm} / \mathrm{s})$.

O estudo de Santos et al. ${ }^{20}$ faz a utilização da plataforma de força em Fisioterapia na amputação do membro inferior, através de uma revisão bibliográfica de artigos experimentais, onde a plataforma de força foi usada em pacientes amputados unilaterais do membro inferior para estudar o equilíbrio e/ou marcha, obteve como resultados pacientes iniciantes na utilização da prótese teve menor oscilação postural e maior segurança, com apoio da perna contralateral a amputação do que no membro inferior com a prótese, isso se dá pelo ganho de equilíbrio adquirido pré-amputação com apoio no membro não afetado e por não ocorrer a descarga de peso no membro afetado devido a dor que a aterosclerose provoca, causando a diminuição da função, porém o treino de propriocepção e equilíbrio pós-protetização e familarização com o equipamento foi implantado, fazendo os pacientes se sentirem mais seguros em distribuir o peso nos dois membros inferiores; por isso os pacientes protetizados experientes conseguem manter uma adequada postura bipodal.

As malformações congênitas e amputações em MMII podem gerar alterações posturais. Prim et al. ${ }^{21}$ afirmam que as anormalidades geradas pela amputação têm principal relação postural, devido aos encurtamentos musculares principalmente de adutores e abdutores, que podem gerar alterações significantes em relação às escolioses. Como foi demonstrado por Braz et al. ${ }^{22}$, a postura adotada anterior pelos pacientes amputados de membros inferiores, o desequilíbrio muscular é o principal responsável por essa alteração. Neste estudo foi observado que a malformação levou o paciente a adotar posições de 
compensações musculares para suprir as necessidades da anormalidade do membro inferior, gerando uma desordem musculoesquelética, como consequência a escoliose, protusão de ombro, anteriorização da cabeça, entre outros.

Realizada também a avaliação postural visual, foi possível observar na análise das fotos alterações posturais nas vistas anterior, laterais e posteriores do paciente com e sem a prótese. Em vista anterior sem prótese, o paciente apresentou inclinação de cabeça à direita, ombro direito elevado, triângulo de Thales assimétrico à direita, tronco em rotação à direita, crista ilíaca ântero-superior esquerda mais elevada que a crista ilíaca ântero-superior direita, quadril com rotação externa à direita, coxa direita em adução e joelhos em genovaro.

Em vista anterior com prótese, foi observada inclinação de cabeça à direita, elevação do ombro direito, assimetria direita em ângulo de Thales, tronco em rotação à direita, assimetria da crista ilíaca direita, quadril com rotação externa e em leve flexão à direita e joelhos em genovaro.

Em vistas laterais sem prótese, coluna torácica com hipercifose, coluna lombar com hiperlordose, cintura pélvica em antiversão e flexão do quadril direito. Foram observadas tais alterações nas com prótese: ombros protrusos, coluna torácica com hipercifose, coluna lombar com hiperlordose, cintura pélvica em antiversão.

$\mathrm{O}$ paciente avaliado em vista posterior apresentou tais alterações sem a prótese: escápulas aladas, ângulo inferior da escápula direita mais elevada, coluna toracolombar com escoliose em "C", crista ilíaca póstero-inferior esquerda mais elevada, pregas glúteas assimétricas à direita, pé direito normal e pé esquerdo plano em eversão e com a prótese, apresentou escápulas aladas, ângulo inferior da escápula direita mais elevada coluna toracolombar com escoliose em "C", assimetria das pregas glúteas, pé direito normal e pé esquerdo plano em eversão.

De acordo com Niekerk et al. ${ }^{23}$, há várias décadas a avaliação na postura ortostática tem sido extensamente utilizada em estudos, na elaboração do diagnóstico e na implementação dos tratamentos fisioterapêuticos.

Souza et al. ${ }^{24}$ e Ruivo et al..$^{25}$, de maneira geral, em suas pesquisas referem-se à fotogrametria digital, con- tribuindo na análise biomecânica da postura estática assim como outros variados métodos. A American Society of Photogrammetry define fotogrametria como "a arte, ciência e tecnologia da obtenção de informação confiável sobre objetos físicos e o meio ambiente através de processos de gravação, medição e interpretação de imagens fotográficas e padrões de energia eletromagnética radiante e outras fontes"26.

Em afirmação com Luna et al. ${ }^{27}$, a biofotogrametria computadorizada propagou-se através de princípios fotogramétricos aplicados às imagens para ser interpretadas visualmente e servir como nova ferramenta de estudo. Assim Carneiro et al. ${ }^{28}$, por sua aplicação em diversos estudos e comprovada eficácia, a biofotogrametria computadorizada pode ser utilizada em distintas áreas, sendo aplicada pelos fisioterapeutas na avaliação e diagnóstico físico-funcional.

\section{CONCLUSÃO}

Conclui-se que através da avaliação fisioterapêutica, foi possível identificar alterações posturais, déficit de equilíbrio e diminuição de força muscular no membro inferior direito, o que acarreta uma alteração biomecânica importante no participante avaliado. Essas informações coletadas durante as avaliações são essenciais para promover um melhor direcionamento ao tratamento proposto pelo fisioterapeuta.

\section{REFERÊNCIAS}

1. Ramos AP. Prevalência de malformações congênitas em recém-nascidos em hospital da rede pública. Saúde Com. 2016; 4(1):1215-16.

2. Oliveira FA, Ximenes FJM, Monteiro ACS, Farias ODO, Mendes IC, Silva CFD, Moura DDJM. Competências familiares relacionadas à prevenção e tratamento das doenças nas crianças de até seis anos. Saúde e Pesquisa. 2018; 11(2):257-65.

3. Junior LCH, Carvalho ACA, Costa LOP, Lopes AD. Lower limb alignment characteristics are not associated with running injuries in runners: Prospective 
cohort study. Eur J Sport Scien. 2016; 16(8):113744 .

4. Zamparo P, Pavei G, Nardello F, Bartolini D, Monte A, Minetti AE. Mechanical work and efficiency of $5+$ $5 \mathrm{~m}$ shuttle running. Eur J Appl Physiol. 2016; 116 (10):1911-19.

5. Pastura PSVC, Land MGP. Children with multiple congenital defects: what are the limits between therapeutic obstinacy and the treatment of uncertain benefit? Rev Paul Pediatr. 2017; 35(1):110-4.

6. Balardina AL, Andrighettia S, Schimit VM, Cechetti F, Bonetti LV, Saccani R. Análise Cinemática Linear e Angular da Marcha em Pacientes Amputados Transfemorais Protetizados. J Health Sci. 2018; 20(2): 125-130.

7. Lawson BE, Ruhe B, Shultz A, Goldfarb M. A powered prosthetic intervention for bilateral transfemoral amputees. IEEE Trans Biomed Eng. 2015; 62(4): 1042-50.

8. Treacy D, Schurr K, Lloyd B, Sherrington C. Additional standing balance circuit classes during inpatient rehabilitation improved balance outcomes: an assessor-blinded randomised controlled trial. Age Ageing. 2015; 44(4):580-86.

9. Youm CH, Shin JD, Lee JS, Seo KE, Park JJ. Effects of Localized Muscle Fatigue and Whole Body Fatigue on Postural Control during Single-Leg Stance. Korean J Orthod. 2014; 24(2):111-9.

10. Teixeira LA. Sobre a generalidade de estratégias de controle sensório-motor. Rev Paul Educ Fís. 2017; 3 : 89-96.

11. Silva RA, Vieira ER, Carvalho CE, Oliveira MR, Amorim CF, Neto EN. Age-related differences on low back pain and postural control during one-leg stance: a case-control study. Eur Spine J. 2016; 25 (4):1251-57.

12. Duncan CA, Ingram TG, Mansfield A, Byrne JM, McIlroy WE. Population differences in postural response strategy associated with exposure to a novel continuous perturbation stimuli: would dancers have better balance on a boat? PloS One. 2016; 11 (11).

13. Krause M, Anschütz W, Vettorazzi E, Breer S, Amling M, Barvencik F. Vitamin D deficiency intensifies de- terioration of risk factors, such as male sex and absence of vision, leading to increased postural body sway. Gait Posture. 2014; 39(1):166-71.

14. Rabello LM, Macedo CDSG, Oliveira MR, Fregueto JH, Camargo MZ, Lopes LD, Silva RA. Relação entre testes funcionais e plataforma de força nas medidas de equilíbrio em atletas. Rev Bras Med Esporte. 2014; 20(3):219-22.

15. Barela A, Duarte M. Utilização da plataforma de força para a aquisição de dados cinéticos durante a marcha humana. Brazillian Journal of Motor Behavior. 2011; 6(1):56-6.

16. Duarte M, Freitas SM. Revisão sobre posturografia baseada em plataforma de força para avaliação do equílibrio, Braz J Phys Ther. 2010; 14(3):183-92.

17. Novalo E, Pedalini MEB, Bittar RSM, Lorenzi MC, Bottino MA. Posturografia Dinâmica Computorizada: Avaliação Quantitativa de Pacientes com Vestibulopatia Tratados por Meio de Reabilitação Vestibular. Arq Int Otorrinolaringol. 2008; 12(2):253-7.

18. Funabashi M, Santos-Pontelli TEG, Colafemina JF, Grossi DB. Proposta de avaliação fisioterapêutica para pacientes com distúrbio do equilíbrio postural. Fisioter Mov. 2017; 22(4):509-17.

19. Carvalho EPS, Silva JB, Alencar LL, Jesus RLR, Matos LKBL, Mesquita LSA, Carvalho MEIM. Estabilometria e baropodometria na avaliação do equilíbrio em paciente com malformação de Arnold Chiari submetido a tratamento fisioterapêutico. Ter Man. 2013; $11(53): 355-60$.

20. Santos LDM, Souza TP, Crescentini MCV, Poletto PR, Gotfryd AO, Yi LC. Avaliação postural por fotogrametria em pacientes com escoliose idiopática submetidos à artrodese: estudo piloto. Fisioter Mov. 2012; 25 (1):165-73.

21. Prim GDS, Santos FAS, Vieira M, Nassar V. Estudo comparativo prospectivo para a avaliação da reabilitação de usuários de próteses com amputações transtibiais. Ciênc Saúde Colet. 2016; 21:3183-92.

22. Braz RG, Goes FPDC; Carvalho GA. Confiabilidade e validade de medidas angulares por meio do software para avaliação postural. Fisioter Mov. 2017; 21 (3):117-26.

23. Niekerk V, Louw Q, Vaughan C, Grimmer-Somers 
K, Schreve K. Photographic measurement of upper-body sitting posture of high school students: A reliability and validity study. BMC MusculoskeletDisord. $2008 ; 9(1): 113$.

24. Souza JA, Pasinato F, Basso D, Corrêa ECR, Silva AMT. Biofotogrametria confiabilidade das medidas do protocolo do software para avaliação postural (SAPO). Rev Bras Cineantropom Desempenho Hum. 2011; 13(4):299-305.

25. Ruivo RM, Pezarat-Correia P, Carita AI. Intrarater and interrater reliability of photographic measurement of upper-body standing posture of adolescents. J Manip Physiol Ther. 2015; 38(1):74-80.

26. Karlin Al. Gis Tips \& Tricks. Photogrammetric Engineering \& Remote Sensing. 2016; 82 (9):664-8.

27. Luna NMS, Nogueira GB, Saccol MF, Leme L, Garcia MC, Cohen M. Amplitude de movimento rotacional glenoumeral por fotogrametria computadorizada em atletas da seleção brasileira de handebol masculino. Fisioter Mov. 2009; 22(4):527-35.

28. Carneiro PR, Cardoso BC, Cunha CM, Teles LC.

Confiabilidade inter e intraexaminador da avaliação postural da cabeça por fotogrametria computadorizada. Fisioter Pesqui. 2014; 21(1):34-9.

Recebido em: 01/11/2018

Aceito em: 31/01/2019 